\title{
Aristóteles y Heidegger en torno a la función apofántica del lógos
}

\author{
Aristotle and Heidegger concerning the apophantic function of lógos \\ Fernando Martin De Blassi \\ Universidad Nacional de Cuyo - CONICET, Argentina \\ martindeblassi@gmail.com
}

\section{Resumen:}

Este trabajo analiza la interpretación existencial del habla, que Heidegger desarrolla en el $\$ 34$ de Ser y tiempo. Allí queda planteada la posibilidad de remontarse al uso del término griego $\lambda o ́ \gamma o \varsigma$ para significar el sentido originario de la palabra alemana Rede. El examen remite a fortiori al $\$ 7 \mathrm{~B}$ donde el filósofo propone, entre otros aspectos, la traducción de $\lambda o ́$ yos por "decir”, cuya función

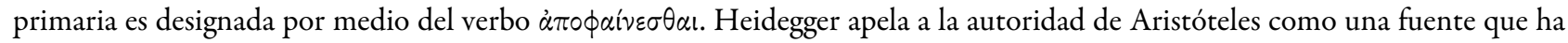
tematizado tal "decir" en cuanto à $\pi^{\phi} \phi \alpha \nu \sigma \iota \varsigma$. En consecuencia, serán considerados los primeros capítulos de De Interpretatione a fin de reconocer los límites y alcances de la comprensión heideggeriana respecto de la definición que el stagirita atribuye al concepto de $\lambda o ́ \gamma \circ \varsigma \alpha \dot{\pi} \circ \phi \alpha \nu \tau i k o ́ s$.

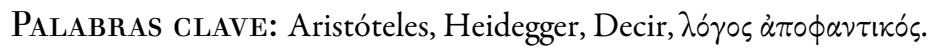

\begin{abstract}
:
This paper analyzes the existential interpretation of language that Heidegger develops in $\$ 34$ of Being and Time. There, Heidegger

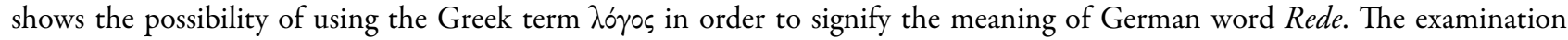
refers a fortiori to a $\$ 7 \mathrm{~B}$ where the philosopher proposes, among other aspects, the translation of $\lambda$ óyos by "saying", whose primary function is designated by the verb $\dot{\alpha} \pi \circ \phi \alpha i v \varepsilon \sigma \theta \alpha$. Heidegger appeals to the authority of Aristotle as a source that has thematized such "saying" as $\dot{\alpha} \pi \dot{\phi} \phi \alpha \nu \sigma \varsigma \varsigma$. Consequently, the first chapters of De Interpretatione will be considered in order to recognize the limits and scope of the Heideggerian understanding regarding the definition that the Stagirite attributes to the concept of $\lambda \dot{o} \gamma \circ \varsigma_{\alpha} \dot{\pi} \circ \phi \alpha v \tau i k o ́ s$.
\end{abstract}

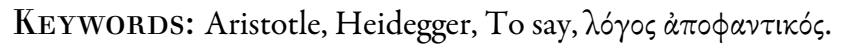

\section{OBSERVACIONES PRELIMINARES}

El tema del $\lambda o^{\prime} \gamma \circ \varsigma$ en el pensamiento de Aristóteles ha sido de una importancia clave para la historia de la filosofía, a la vez que ha suscitado numerosos comentarios y reflexiones a raíz de la polisemia que aquel vocablo entraña. El estagirita lo utiliza no solo en el ámbito fáctico sino también en el noético y, dentro de cada uno, notifica un cúmulo de diversos significados. Junto con otras voces del lenguaje aristotélico, el carácter

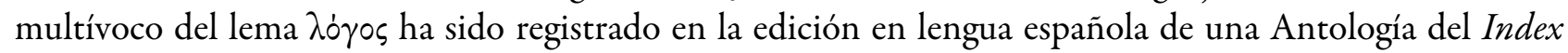
Aristotelicus de H. Bonitz. Ya en la introducción de ese trabajo, sobre la base de la nota de Ackrill al pasaje de De int. IV, 16b 26, Evans Civit (2010, pp. 10-11) afirma que la palabra $\lambda$ ó yos no puede traducirse de manera absoluta, por ser un sustantivo verbal de un verbo cuya función primaria refiere a las acciones de "relatar", "referir", "decir", "hablar". De esta manera, el traductor se ve forzado a adoptar acepciones diferentes según

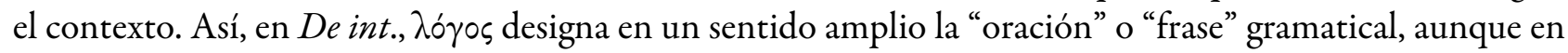
otros pasajes convenga traducir el término griego por los de "explicación" (16b 1, 19a 28, 19b 19, 21b 24), "definición" (17a 11, 21a 29), "declaración" (19 a 33, 23 a 28), "razón”, "razonable" (21b 14, 22a 14) o bien

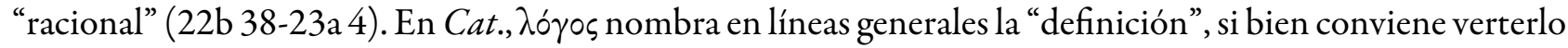
a su vez por "declaración” (4a 22, 12 b 6-10, 14b 14-22), "lenguaje” (4b 23, 4b 32-35, 5a 33-36), "decir” en el sentido de "narrar" (13a 24) o bien de "proferir" (14a 36, 14b 2). 
Con respecto al derrotero de la filosofía en el s. XX, Heidegger es uno de los autores que ha procurado de modo explícito no solo recuperar las voces de $\lambda o ́ \gamma \circ \varsigma$ y $2 \lambda \lambda \hat{\eta} \theta \varepsilon ı \alpha$ en clave fenomenológica, sino también de asociar la concepción tradicional de tales términos con el desenlace intrínseco de la historia de la metafísica.

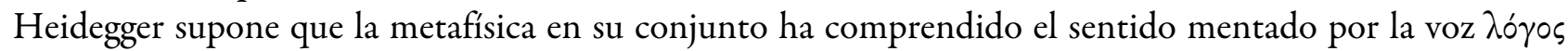
conforme con las notas fundamentales de la proposición asertiva. Para la mirada heideggeriana, la fatalidad conllevada en este modo de comprender el significado de $\lambda o ́$ yos es doble. Por una parte, él considera que la lectura metafísica del concepto de $\lambda$ ó ${ }^{\circ} \varsigma$ ha procedido de acuerdo con la esencia de la técnica; por otra, semejante interpretación ha posibilitado la representación de una estructura verbal judicativa, capaz de reflejar la verdad del ser del ente y de sus aspectos constitutivos (Boeder, 2003, p. 6; 2003, p. 21 ss). Haciendo del lenguaje un instrumento al servicio del dominio de la razón, Heidegger (1994, pp. 163-178) subraya que la metafísica impide al lenguaje manifestarse como una morada donde habita el ser humano. De modo que su propuesta metódica se centra en ir del habla hacia el lenguaje y no a la inversa. Por tales motivos, Heidegger sostiene que el enunciado apofántico no atañe stricto sensu al lugar de la verdad pues esta última, entendida como des-ocultación, constituye previamente el lugar del enunciado, que deriva a su vez del habla. En la Carta sobre el humanismo, Heidegger (2006, pp. 38-39) asevera que el hombre se encuentra arrojado, toda vez que su destino consiste en ser el pastor del ser. Si bien el hombre no tiene en sus manos decidir de qué manera acontezca el advenimiento del ente en el claro del lenguaje, la meditación heideggeriana caracteriza lo esencialmente humano como una apertura en la custodia por la verdad del ser. Tal condición destinal es lo único que pretende pensar Ser y tiempo $(=\mathrm{SuZ}),{ }^{1}$ cuando se pregunta por la existencia como cuidado.

En el $\$ 34$ de $S u Z$, el filósofo alemán ofrece una interpretación de cuño existencial en relación con el fenómeno del habla (Rede). Allí queda planteada la posibilidad de remontarse al uso griego del vocablo $\lambda o ́ \gamma o s$ para deslindar el sentido originario de la palabra alemana Rede. En el $\$ 7$ B de la misma obra, Heidegger propone, entre otros aspectos, la traducción de $\lambda$ ó $\varsigma_{\varsigma}$ por "decir", cuya función primaria estaría vinculada con el verbo $\dot{\alpha} \pi \circ \phi \alpha i v \varepsilon \sigma \theta \alpha$ l. Heidegger acude a la autoridad de Aristóteles como una fuente que habría visto

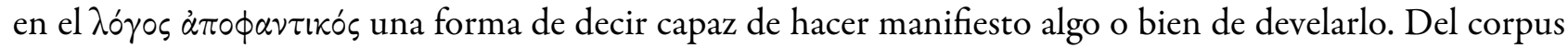
aristotélico, Heidegger cita tres títulos: De int., Met. y Eth. Nic. puesto que, según su parecer, en determinados pasajes de aquellas obras el estagirita habría mostrado con más claridad el sentido del "decir" en cuanto $\dot{\alpha} \pi \dot{\phi} \alpha \nu \sigma \iota \varsigma$.

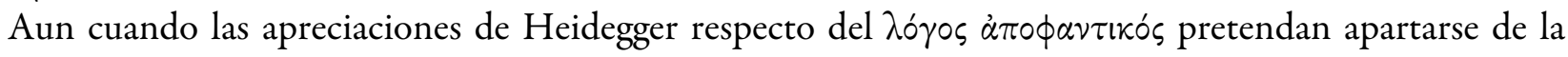
tradición metafísica, debe señalarse empero que el Organon ofrece la reflexión del estagirita sobre las formas fundamentales del pensar en relación con el saber. Para el maestro del Liceo, el orden lógico se despliega a causa de la verdad a partir del $\lambda o ́ \gamma \circ \varsigma$, más aún, según la índole sintética que le es propia, toda vez que vincula y

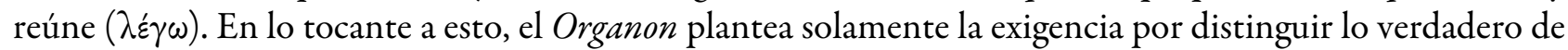
lo falso partiendo, primero, de la categorías en cuanto materia de su primer libro; luego, de la conformación de la proposición enunciativa en De int. hasta dar con la estructura del razonamiento, más precisamente, la articulación completa de sus figuras en los Analytica priora. El tema en cuestión radica sobre todo en el análisis

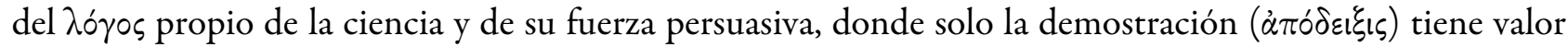
científico porque vincula proposiciones necesarias cuyo principio reside en el intelecto (voṽs). Por medio de la Analítica, el entendimiento se vuelve capaz de ciencia. La pregunta de Aristóteles gira, entonces, en torno a qué consiste la potencia persuasiva del $\lambda o ́ \gamma o s$. De allí que la formación del entendimiento se relacione con la naturaleza de esta capacidad argumentativa, en la medida en que tiene la obligación de ofrecer una explicación acerca del fundamento de los principios de la ciencia (Boeder, 2003, p. 14 ss).

En el orden de las consideraciones que se han venido realizando, se advierte por tanto que la explicación de Heidegger acerca del enunciado asertivo debe ser cotejada con el debido detenimiento a partir de lo sostenido en rigor por la fuente aristotélica. El filósofo alemán entiende que el enunciado es visto por Aristóteles como un decir que puede ser falso o verdadero, cuya extensión es válida para todo modo de decir hablante. A causa de esto, el enunciar ( $\dot{\pi} \pi \dot{\phi} \phi \alpha \nu \sigma \iota \varsigma)$ y su carácter verdadero o develador derivan del habla como de su 
estructura originaria $(\lambda \varepsilon ́ \gamma \varepsilon \sigma \theta \alpha \iota)$. Esta lectura de Heidegger ignora, empero, un componente imprescindible del enfoque aristotélico acerca del triángulo semántico. Se trata, precisamente, del ente real y del fundamento que posibilita su intelección en el plano del notificar. Para Aristóteles, toda verdad del enunciado asertivo está dada, en definitiva, por la referencia del orden intelectivo al inteligible. Esto quiere decir que la condición tanto del decir verdadero como de la verdad misma se acredita en virtud de la estructura ontológica del ente y no de la relación pragmática favorecida por los diversos interlocutores.

Heidegger manifiesta, por lo demás, que el enunciado apofántico es el hablar que solo hace ver. Cabe preguntar, entonces: ¿hace ver qué cosa?, puesto que si es un hablar no podría serlo de cualquier tema o asunto. $\mathrm{Si}$ en Aristóteles el enunciado es revelador, ello estriba en su capacidad para determinar de qué manera el

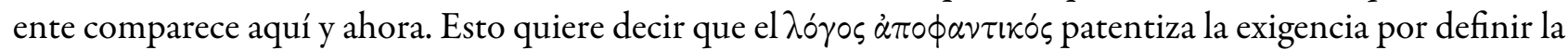
posición de existencia del ente y "lo que le corresponde de suyo" (Met. 1003a 21-22) en virtud de su propia estructura categorial: la ovं $\sigma i \alpha$ junto con el resto de los praedicamenta. Por consiguiente, en esta oportunidad se acometerá una indagación descriptiva y analítica de los $\$ 34$ y 7 B de $S u Z$, junto con la de los cp. 1-6 de $D e$ int., a fin de ponderar los límites y alcances del planteo excogitado por el filósofo alemán en torno al $\lambda o ́$ os

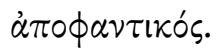

Entre los años 1925-1926, Heidegger dictó unas conferencias académicas en su condición de Prof. Extraordinario de la Universidad de Marburgo, editadas luego por W. Biemel. Estas conferencias contienen muchas de las ideas que fueron sistematizadas posteriormente en SuZ (Bertorello, 2008, p. 121 ss; Escobar, 2004, pp. 361-362; Molina, 2012, pp. 1-9). En su conjunto, se titulan: Lógica. La cuestión acerca de la verdad y constan de tres partes. La primera se denomina: El problema de la verdad en el comienzo decisivo de la lógica que filosofa y las raices de la lógica tradicional. En ella se ofrece una interpretación propia de cómo Aristóteles plantea el problema de la verdad en $D e$ int. Por esta razón, sumada a otra no menor sobre los límites a que obliga la extensión del presente trabajo, se prescindirá aquí de abordar los pasajes de Met. y de Eth. Nic.citados por Heidegger, reservándolos para una investigación futura. A pesar de que tales referencias contribuyan a

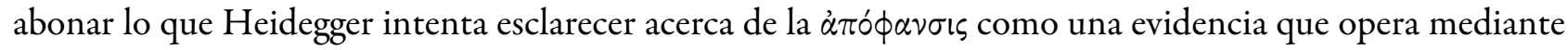
el decir develador, no es necesario acudir a otros fragmentos complementarios pues el texto de De int. ya es suficiente para encauzar este estudio.

\section{LA INTERPRETACIÓN EXISTENCIAL DEL HABLA A PARTIR DE LA ANALÍTICA EXISTENCIARIA DEL DASEIN}

\section{Dasein y lenguaje}

En el $\$ 34$ de SuZ, Heidegger (2003, pp. 478-479) desarrolla el tema del lenguaje (Sprache) cuyo fundamento ontológico, a la vez que existencial, reside en el habla o discurso (Rede). Este tema sirve tan solo para indicar que el fenómeno del lenguaje tiene su raíz en la constitución existencial de la condición de lo abierto del Dasein. El discurso no es el lenguaje sino que el lenguaje atañe a la exteriorización óntica —en palabras, signos, gestos- de aquella estructura ontológica previa, denominada Rede. Antes de cualquier interpretación, el enunciado descansa sobre la base del discurso. En este sentido, el discurso articula la posibilidad de comprensión que es susceptible de ser apropiada de manera verbal. En las consideraciones previas acerca de la disposición afectiva, del comprender y del enunciado interpretante, Heidegger acude constantemente al fenómeno del lenguaje, si bien sustrayéndolo de un análisis temático. Él comenta que este apelar al lenguaje se torna visible a partir del esclarecimiento del enunciado como expresión verbal o comunicativa (SuZ \$34, pp. 183-184; $\$ 33$, p. 178 ss).

En términos existenciales, la estructura propia del habla o discurso es previa a toda interpretación, dado que refiere a un modo posible de articulación. Por ello, el habla denota la articulación de un todo significativo 
en el modo de la circunspección. La comprensión cotidiana del mundo tiene la forma de una circunspección. En ella, es comprendido un complejo de remisiones en cuanto trato ocupado con los útiles, es decir, es comprendida la estructura ontológica del útil en su para-qué (Astrada, 1952, pp. 45-57). Por su parte, la interpretación apropia significativamente la estructura de ser de un ente determinado (SuZ \$31, p. 168). En la medida en que interpreta, el Dasein se apropia de lo ya comprendido porque lo supone ya explícito (SuZ \$32, p. 172). El carácter proyectivo del comprender constituye, a su vez, la visión (Sicht) del Dasein. Esta visión se da existencialmente junto con la apertura del ahí y no mienta otra cosa más que el Dasein mismo en sus distintas maneras fundamentales de ser, ya aclaradas y con igual condición originaria en todas ellas. Con respecto a la solicitud consigo mismo, el Dasein se ocupa de una visión por-mor-de la cual es siempre como es (SuZ\$31, pp. 169-170).

En el caso del trato ocupado con los útiles intramundanos, siempre hay un ver en la circunspección, previo al todo de remisiones, desde donde puede explicitarse el útil en su carácter de estar-a-la-mano para algo (SuZ $\$ 18$, p. 109 ss). La circunspección subordina para sí el mundo dado. En cuanto estructura de significación ya articulada, la circunspección suministra la utilidad propia del útil. Al interpretarlo, cada uno se apropia de él en el uso. Asimismo, el útil se vuelve explícito al ser utilizado, es traído al frente en cuanto que se vuelve algo presente ahí. El útil es apropiado de manera significativa tras haber sido previamente comprendido en la circunspección. En esto último consiste la estructura propia en cuyo marco se articula todo modo de ver conforme con la circunspección (SuZ \$32, pp. 172-173).

Por lo que concierne a la existencia, ella se determina estructuralmente como ser-en-el-mundo y, en cuanto tal, implica un abrir significativamente el propio ser-en-el-mundo. De modo tal que el Dasein abre, cada vez, su propio ser-en-el-mundo. En el Dasein, la significatividad y el por-mor-de se encuentran abiertos, esto quiere decir que el Dasein es el ente al que, en cuanto estar-en-el-mundo, le va su propio ser (SuZ \$31, p. 167). La apertura significativa de la propia existencia que el Dasein explicita en su modo de ser ahí, se efectúa a partir de tres modos co-originarios: el comprender, la disposición afectiva y el habla o discurso $(S u Z \$ 29$, pp. 31 y 34; \$34, p. 184). En cuanto articulación significativa, el habla está co-implicada en la comprensión que el ser humano tiene de sí mismo, de los otros, del mundo y de las cosas. No hay comprender que no sea por lo mismo hablante (SuZ \$34, pp. 183-184). Como Dasein quiere decir estar-en-el-mundo y, por lo demás, como el discurso es constitutivo del ser del ahí junto con la disposición afectiva y el comprender, el Dasein en cuanto estar-en ya se ha expresado en palabras. Es hablante. Tiene lenguaje.

El Dasein en cuanto ser-ahí implica una apertura.l es un estar abierto porque primeramente es un estar abriendo, un estar hablando. El comprender alude a un proyectar sentido, es decir, al hecho de abrir la posibilidad de la comprensión. De allí que toda forma de articular la proyección significativa se exprese como habla (SuZ \$34, p. 184). Entretanto, el habla ostenta el resultado que surge articuladamente a partir de un todo de significaciones. De allí que, a propósito del discurso, Heidegger afirme que el carácter articulado de las significaciones se halla cada vez afectivamente dispuesto como una posibilidad de comprender el propio estar-en-el-mundo ( $S u Z$ \$34, p. 185). Por consiguiente, el habla y el complejo significativo se implican mutuamente. El habla hace referencia a la articulación; el sentido, a lo que puede ser articulado y el complejo significativo - el todo de significación o el mundo como posibilidad infinita de apertura- se refiere a lo articulado propiamente dicho.

Hacia el final del \$34, el filósofo alemán se interroga de la siguiente manera: “¿Será un azar que los griegos, cuya existencia cotidiana tomaba predominantemente la forma de diálogo, y que, además, 'tenían ojos' para ver, hayan determinado la esencia del hombre, en la interpretación prefilosófica y filosófica del Dasein, como

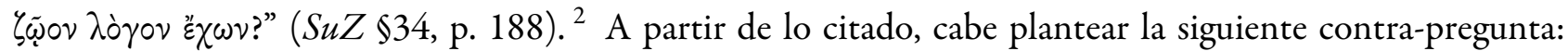
¿Qué tipo de interpretación se quiere desentrañar? ¿Acaso Heidegger pretende justificar su propia teoría del lenguaje desde alguna posición ya establecida en el marco integral de la historia de la filosofía? El remontarse al vocablo griego $\lambda o ́$ yos se orienta, por de pronto, para indagar hasta qué punto en el empleo originario de esa palabra se encuentra testimoniado el habla existencial. A propósito de ello, Heidegger afirma que los griegos 
no tenían ninguna palabra para designar el lenguaje. Por el contrario, ellos comprendieron este fenómeno inmediatamente como discurso. La posterior interpretación del hombre como animal rationale, no ha hecho más que encubrir el terreno fenoménico de donde fuera tomada la definición del hombre como un ente que habla. Es decir, no tanto un ser que tiene la posibilidad de comunicarse por medio de la voz, sino en cuanto que este ente es en la forma del descubrimiento del mundo y del mismo Dasein (SuZ \$34, pp. 186-188).

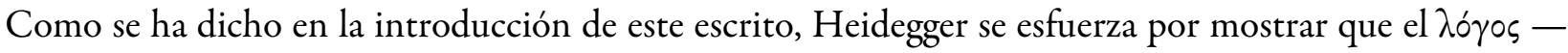
uno de los conceptos fundamentales de la filosofía - no puede ser reducido a la teoría del juicio de la lógica tradicional, es decir, al enunciado teorético de la forma: $S(e s)$ P. Este tipo de enunciado sería solo una de las tantas modalidades que el $\lambda$ ó yos podría asumir y, con todo, la menos originaria. En este contexto, A. Bertorello (2008, pp. 121 ss.) entiende que Heidegger desarrolla una explicación genética del enunciado a partir de un análisis semántico que muestra cómo los juicios de la lógica clásica son un modo derivado de las relaciones semánticas puramente prácticas en las que el Dasein está envuelto en su mundo. Según Bertorello, la tesis de Heidegger sobre el problema del enunciado podría resumirse en los siguientes términos: el rasgo primario del enunciado radica en su función referencial o en su carácter apofántico. Esta función tiene su condición de posibilidad en un rasgo estructural de la vida humana que Heidegger denomina comprensión interpretativa (auslegendes Verstehen). De allí que el enunciado sea calificado como un derivado de la interpretación. En el \$34, Heidegger utiliza el término alemán Rede para designar por medio de él el habla o discurso. Esta misma palabra había sido empleada también en el $\$ 7$ B para traducir el vocablo griego $\lambda$ ó $\gamma \circ$ s, el cual hacía referencia al decir en su carácter mostrativo o notificante. Desde esta nueva perspectiva, se examinará a continuación el contenido del $\$ 7 \mathrm{~B}$ a fin de dar con la interpretación existencial de $\lambda o ́ \gamma \circ \varsigma$, cuya función primaria Heidegger asocia con la del vocablo ả

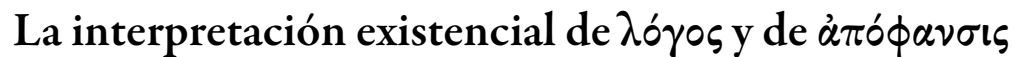

Dentro del desarrollo que se lleva a cabo en $S u Z \S 7$ B acerca de la locución $\lambda o ́$ yos, se advierte que Heidegger busca distanciarse principalmente de la comprensión tradicional de $\lambda o ́ \gamma o \varsigma$ en cuanto juicio. Asimismo, se aparta también de la concepción de verdad entendida como adecuación o concordancia. Para él, $\lambda o ́ \gamma o s$ designa fundamentalmente un "hacer ver" al que debe atenderse en el sentido de un prestar oído. En consecuencia, $\lambda o ́$ yos entraña un atender en el orden del corresponder.

Señalando que $\lambda$ ó $\gamma \circ \varsigma$ es el fundamento de todo interpelar o discurrir posibles, como aquello que se hace visible en su remisión a algo, E. Muñoz Pérez (2013, pp. 215-225) considera que esta indagación acerca de $\lambda o ́$ yos es aplicada, incluso, al ámbito en que se lo designa como razón de ser del discurso. Heidegger busca

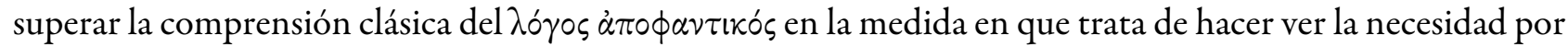

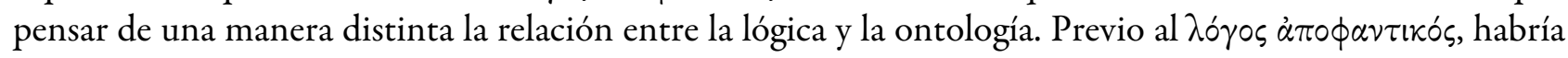
que tener presente un $\lambda o ́ \gamma o s$ existencial o hermenéutico que dé cuenta de la profundidad de la existencia humana. Y esto quiere decir que la lógica, junto con sus enunciados, no puede ser comprendida únicamente como el vestíbulo del conocimiento. Más aún, el enunciado lógico no puede negar su origen ontológico en la interpretación fundada a partir del comprender ( $\mathrm{SuZ} \$ 32$, p. 172 ss). En esta valoración, Heidegger pone el énfasis en la constitución existencial del ser del ahí y su condición fáctica de arrojado. Por medio de su comportamiento fundado en el $\lambda o ́ \gamma \circ \varsigma$, puesto que en un decir develador, el Dasein puede vincularse con el resto de los entes, comprenderlos en su conjunto y reflexionar sobre ellos. A partir de esta relación de sentido, el Dasein configura su mundo.

Heidegger expresa que $\lambda$ ó $\gamma \circ \varsigma$ ha sido interpretado generalmente como razón, juicio, concepto, definición, fundamento, relación. Sin embargo, estas versiones no harían sino encubrir o alejarse del sentido primario y fundamental que encierra aquel vocablo para la lengua griega. En el plano etimológico, $\lambda o ́ \gamma o s$ procede del verbo $\lambda \varepsilon \dot{\gamma} \gamma \omega$, cuyo significado original es "ordenar", "recolectar" y, por tanto, "escoger". $\lambda o^{\prime} \gamma o \varsigma$ es un vocalismo antiguo de gran importancia. En Homero, se refiere a las palabras o discursos (Il. 15, 393; Od. 1, 56), 
mientras que en los dialectos jónico y ático presenta diversas acepciones: "relato, recuento, consideración, explicación, razonamiento, razón, palabra”, todas ellas por oposición al sintagma $\tau \dot{\alpha}$ ép $\gamma \alpha$ (Chantraine, 1974, pp. 625-626). Heidegger manifiesta que incluso cuando se entienda el $\lambda$ ó juicio, esa traducción puede no dar con su significado elemental, sobre todo si el juicio es concebido como síntesis de representaciones o bien como enlace (SuZ \$7 B, p. 55).

De acuerdo con el planteo heideggeriano, $\lambda o ́$ yos significa fundamentalmente "decir" (Rede). Él afirma que la traducción literal de $\lambda o ́ \gamma o s$ por "decir" cobrará validez en virtud de la determinación de lo que significa el decir mismo. Dicha traducción sería de índole más originaria que las restantes interpretaciones ofrecidas por la historia de la filosofía. Rivera (Heidegger, 2003, p. 460) comenta que, en este pasaje, Heidegger está

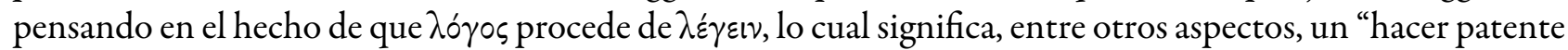
mediante el lenguaje". De allí que $\lambda o ́ \gamma \circ \varsigma$, en su consideración primaria, estaría emparentado con el vocablo $\delta \eta \lambda \circ \tilde{v}$, esto es, un hacer ver mostrativo. Por tanto, en cuanto "decir", $\lambda o ́ \gamma o \varsigma$ significa tanto como $\delta \eta \lambda \circ \tilde{v}$ : un hacer patente aquello de lo que se habla en el decir (Heidegger, 1994, p. 184).

Con todo, Heidegger insiste en que la función primaria del $\lambda o ́$ yos quedará aclarada a partir de la interpretación del decir apofántico. La interpretación pretende captar adecuadamente el significado fundamental de $\lambda o ́$ yos en su contenido primario, puesto que ya en Platón y Aristóteles este vocablo designa una multiplicidad de significaciones (Ast, 1956, pp. 253-258; Bonitz, 1955, pp. 433-437) que, en apariencia, tienden a separarse unas de otras sin la orientación positiva de una significación fundamental. El filósofo alemán asevera que ha sido Aristóteles quien ha caracterizado esta función del decir como un ả (SuZ $₫ 7$ B, pp. 55-56) y, para justificarlo, cita las obras del estagirita donde esa tesis podría verse confirmada (De int., cap. 1 - 6; Met.Z, 4 y Eth. Nic. Z).

El filósofo alemán desarrolla a continuación una lectura de lo que significa, en clave originaria, el concepto de $\dot{\alpha} \pi \circ \phi \alpha i v \varepsilon \sigma \theta \alpha \iota$ como función primaria del decir develador. Afirma que el $\lambda o ́ \gamma \circ \varsigma$ hace ver algo, conviene a saber: aquello de lo que se habla. A su vez, el $\lambda o ́$ yos lo hace ver tanto para el que lo dice cuanto para quienes

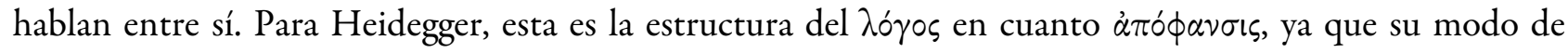
patentizar es propio del hacer-ver que muestra $\left(S u Z \$ 7 \mathrm{~B}\right.$, p. 55). Por su parte, la preposición ả $\pi_{0}$ designa

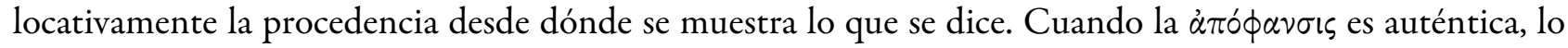
dicho (dictum) debe extraerse de aquello (unde) de lo que se habla, a fin de que la comunicación hablante haga patente en lo dicho aquello de lo que se habla. El decir no solo vuelve accesible aquello de lo que se habla sino también que lo hablado se manifiesta en y desde el decir mismo. En y por el decir se hace visible lo que se habla desde aquello mismo de lo que se habla.

A causa del sentido más originario del término ả $\pi \circ \phi \alpha i v \varepsilon \sigma \theta \alpha \iota$, Heidegger ajusta la traducción del predicado apofántico como un "mostrar desde", esto es, como un hacer ver un ente desde sí mismo. El mostrar (Aufzeigung) es, de esta manera, el primero de los sentidos de un enunciado. Un segundo sentido, en referencia expresa a la predicación, implica el hecho de comprender la proposición como un determinar (Bestimmung). Este segundo nivel hace hincapié en el carácter sintético de las proposiciones y manifiesta, a la vez, el hecho de que el enunciado, al decir algo de algo, se ajusta a la estructura formal: $S$ (es) P. Heidegger arguye que el carácter predicativo es derivado del carácter apofántico y no a la inversa. Un tercer sentido consiste en el aspecto comunicativo del enunciado (Mitteilung). Este último remite a la participación de varios interlocutores y se trata igualmente de un modo derivado del apofántico (SuZ \$33, pp. 178-179).

En su realización concreta, el decir tiene el carácter de un hablar ( $\phi \omega \nu \eta ́)$, de una comunicación vocal en

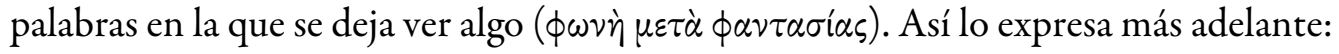

El fenómeno de la comunicación - como ya se indicó al hacer su análisis- debe ser comprendido en un sentido ontológicamente amplio. La 'comunicación' enunciativa, por ejemplo informar acerca de algo, es un caso particular de la comunicación entendida en un sentido existencial fundamental. En ésta se constituye la articulación del convivir comprensor (SuZ \$34, p. 185). 
De esta manera, el $\lambda o ́ \gamma o \varsigma$ puede tener la forma estructural de una $\sigma \dot{v} v \theta \varepsilon \sigma \iota \varsigma$. Síntesis, empero, no significa tanto "enlace" o "conexión" de representaciones, cuanto un "hacer ver algo" en su estar puesto $(\tau i \theta \eta \mu l)$ junto con ( $\left.\sigma v^{\prime}\right)$ algo. Heidegger señala que al definir al $\lambda o ́ \gamma \circ \varsigma$ como una actividad sintética de representaciones, se torna forzoso el problema sobre cómo los procesos psíquicos internos concuerdan con lo físico que está fuera. $^{3}$

De acuerdo con las distinciones dilucidadas, podría afirmarse que Heidegger propone una reinterpretación

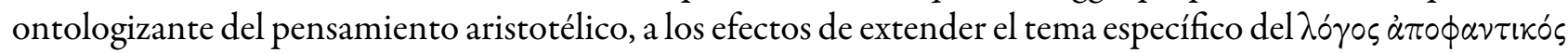
más allá del enunciado mismo. Con respecto a esto último, Escobar (2004, pp. 361-390) ha estipulado que la crítica heideggeriana intenta mostrar el enraizamiento del enunciado en la apertura al mundo. Motivo por el cual, el juicio, que es el lugar estricto de la verdad concebida tradicionalmente como adaequatio, conllevaría un carácter derivado respecto de la des-ocultación del ente en la apertura originaria del Dasein. Acudiendo a Aristóteles, Heidegger manifiesta que la enunciación es solo una forma derivada del habla. A pesar de que en la obra del estagirita, el fenómeno de la verdad esté vinculado con un solo tipo de proposición, la apofántica, para el filósofo alemán la función apofántica sería extensible a todo fenómeno lingüístico. Heidegger emplea

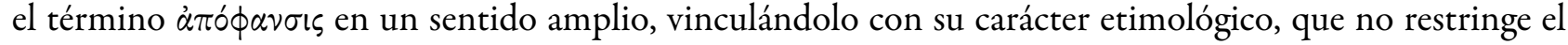

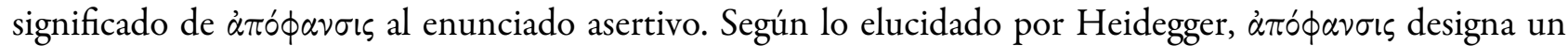
"dejar ver", un "mostrar" en cualquier tipo de orden de los usos del lenguaje e, incluso, en vista de la totalidad de las relaciones teóricas y prácticas que pueden establecerse con el ente.

Es cierto que en el corpus aristotélico hay una alusión a otros tipos de verdad, ${ }^{4}$ pero la verdad en que se ocupa el estagirita en De int. es, con propiedad, la concerniente al ámbito científico. Heidegger, en cambio, pretende indagar en las condiciones ontológicas de la verdad y en el carácter del Dasein como ser-descubridor. Así, él procura mostrar que la forma de verdad discutida en $D e$ int. no es la del fenómeno originario que presenta el vocablo ả $\pi \circ \phi \alpha i v \varepsilon \sigma \theta \alpha$, sino que lo presupone. Precisamente por ello, Heidegger lleva a cabo una interpretación ontologizante del texto aristotélico, partiendo desde el análisis de la estructura formal del enunciado hasta el estado de abierto en el que, en definitiva, se funda la posibilidad de la verdad, puesto que el enunciado será verdadero toda vez que muestre o deje ver al ente en su estado de descubierto $(S u Z \$ 18$, p.

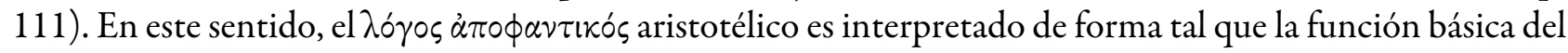
lenguaje estribe en "hacer ver' aquello de lo que se habla. Para Heidegger, tal es el sentido primario de toda proposición enunciativa, un sentido comunicativo, por el simple hecho de que, hablando con alguien acerca de algo, se hace patente el sentido genuino de ese algo.

Ello no obstante, la interpretación existencial de la función apofántica del $\lambda o ́ \gamma o s$, sustentada a partir de la autoridad de Aristóteles, no responde a lo que el estagirita desarrolla explícitamente en De int.A continuación, se procederá en la elucidación de esta materia.

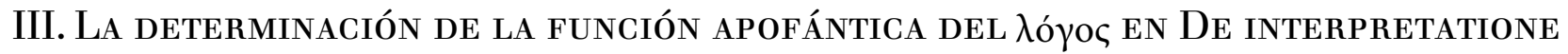

\section{¿De qué manera se comprende lo lógico en Aristóteles?}

Por la tradición y por el orden canónico en que fueron establecidos, se denominó Organon a los escritos de Aristóteles que, de una manera u otra, abordan los temas relacionados con la materia lógica. Tal como su nombre lo indica: una especie de instrumento o auxiliar del pensamiento en vista de su formación científica. El Organon no es considerado, precisamente, una parte sustantiva del conocimiento científico, ni tampoco una ciencia particular junto con las demás ciencias que el estagirita puntualiza para el estudio de la realidad. Antes bien, se trata de una suerte de herramienta al servicio del conocimiento científico en general y del entendimiento cognoscente en particular, a los efectos de recibir una enseñanza acerca de cuáles 
formulación del principio. Este mismo procedimiento es descripto por Aristóteles en otros pasajes semejantes de su obra (Soph. elenchi 167a 23 ss; De int. 17a 35 ss). Ahora bien, en estos casos, cuando él usa el vocablo

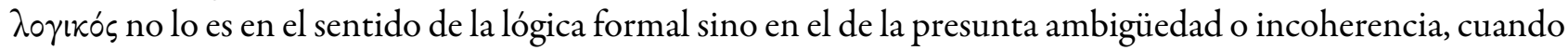
no error, dentro del ámbito argumentativo. En definitiva, para Aristóteles las dificultades lógicas son aquellas que se presentan porque la discusión ha tomado visos de una generalidad tan abstracta que ya poco o nada tiene que ver con el asunto por indagar. Esto les reprocha tanto a los platónicos cuanto a los sofistas, cuyos argumentos implican numerosas contradicciones o bien caen en el absurdo. Es claro que, en Aristóteles, la doctrina lógica difiere de la lógica formal: el pensamiento del estagirita atiende a la cosa misma del pensar, la lógica formal tiene en cuenta la coherencia y validez de la estructura proposicional. ${ }^{8}$

Con todo, puede afirmarse a partir de lo dicho que el término "lógica" no significa para Aristóteles la lógica qua disciplina sino, antes bien, el carácter dialéctico o abstracto de los razonamientos. Cuando el estagirita desarrolla el estudio de los razonamientos y su respectivo análisis en las figuras del silogismo, se trata por cierto de una disciplina denominada Analitica y no Lógica, que puede extenderse hasta incluir en ella el análisis del silogismo en proposiciones y las proposiciones en términos (Anal.pr. 46a 31 ss., 47a 1 ss.). Dentro del Organon, dos libros se ocupan en la temática específica vinculada con las formas válidas de inferencia y, en estrecha conexión con ellas, también con la teoría de la demostración científica. A esta doctrina Aristóteles dedica el conjunto de obras tituladas Analytica priora et posteriora. Esta se enfoca en el carácter demostrativo del razonamiento: apunta a una lógica de la verdad; aquella pone su interés en el deslinde de la estructura formal que debe reunir todo silogismo con independencia de su contenido: es una lógica de la coherencia.

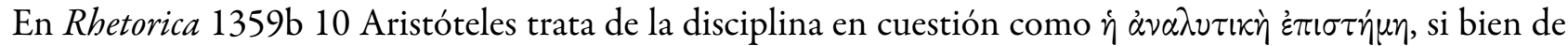
un modo colateral y sin mayores detenimientos. El resto de las obras que componen el Organon guardan una conexión laxa con esta temática central, pues se ocupan en el tema de los términos y los enunciados (Cat. y De interp.), de los modos característicos de la argumentación dialéctica (Topica) o bien de las formas más usuales de falacias empleadas en la argumentación sofística (Soph. elenchi).

Como se ve, el cuerpo de tales tratados está muy lejos de proveer lo que sería una especie de sistematización integral de la lógica en el sentido moderno del término. Desde este punto de vista, Kant habría tenido razón al decir que Aristóteles no agotó el sistema de los conceptos del entendimiento puro, sino que se limitó a deducir la tabla de las categorías a partir de la experiencia, mediante una explicación de cuño descriptivo (KrV B 89-90, 107). Lo cierto es que, a pesar de esta crítica, el tratamiento de los elementos y principios, que en el Organon rigen el conocimiento demostrativo, goza de una cohesión temática a la vez que literaria y conforma una cierta totalidad en relación con sus lineamientos fundamentales. Ya se deba a su situación histórica o bien a sus mismos presupuestos ontológicos, el hecho de presentar de antemano la arquitectónica de la ciencia por medio de la interconexión de sus elementos no es el modo en que procede el estagirita cuando pretende abordar un asunto en particular. Un paso ineludible en la praxis indagatoria de Aristóteles reside en la recolección y correspondiente exposición de $\operatorname{los}^{2} \mathcal{\nu} \nu 0 \xi \alpha$ como lo creído en sentido amplio, latente o explícito, tanto en las estructuras de la lengua cuanto en las acciones de los hombres. Los libros I de Met., Eth. Nic. y De anima muestran de qué manera, antes de ingresar in medias res, Aristóteles apela a lo admitido por los $\check{\varepsilon} \nu \delta \circ \xi \alpha \pi \rho \tau \alpha \dot{\sigma} \sigma \varepsilon ı$ en cuanto creencias comunes que gozan del aval de los expertos o de la comunidad (Chichi, 1997, pp. 180-187).

Cabe añadir que el estudio analítico dentro de la filosofía aristotélica, a diferencia de la gramática o la psicología, no versa acerca de las palabras o su consecuente evolución en la historia de la lengua sino del pensamiento, en la medida en que echa mano a las palabras en su intento por aprehender la naturaleza de las cosas y expresarla de modo verdadero, puesto que científico. Por lo que concierne al presente trabajo, De int. constituye una buena introducción a los Analíticos por dos razones: proporciona un análisis semántico y gramatical de los elementos del enunciado, requisito necesario de una lógica adherida al lenguaje natural como corresponde a la aristotélica y porque, además, analiza desde el punto de vista lógico los elementos atómicos del razonamiento, esto es, las aserciones. De allí que brinde una propedéutica necesaria 
para adentrarse en el estudio sistemático del razonamiento en general (Anal. pr.) y de la metodología del conocimiento científico (Anal. post.) (Candel Sanmartín, 2007, p. 293 ss.).

\section{El objeto de consideración en De int. a partir del análisis del fenómeno lingüístico}

En De int. Aristóteles abordará fundamentalmente la estructura del enunciado que se constituye a partir de los términos dichos sin combinación o categorías. Aduce que su objetivo consiste en explicar qué es el nombre (övo $\mu \alpha)$ y el verbo ( $\dot{p} \tilde{\eta} \mu \alpha)$, para luego estudiar, sobre la base de ello, qué es la negación ( $\dot{\alpha} \pi o ́ \phi \alpha \sigma \varsigma)$ y la

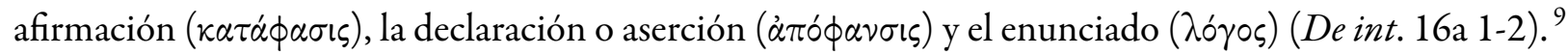

$\mathrm{Al}$ comienzo del tratado, Aristóteles expone una teoría de la significación que establece una interpretación convencional del lenguaje, en la medida en que lo simbólico está constituido por sonidos y grafías fijados históricamente (Coseriu, 1977, pp. 23-24): la escritura es “símbolo" — una señal convencional- de la palabra hablada que, a su vez, es símbolo de las imágenes o afecciones presentes en el alma de los interlocutores. ${ }^{10}$ El estagirita explica que tales imágenes, así como las cosas de las cuales estas son semejanzas, son las mismas para todos. Sin embargo, los sonidos articulados y la escritura difieren de ellos pues varían de un pueblo a otro. Asimismo, en el campo simbólico, las partes semánticas de algo pronunciado $(\lambda \varepsilon \dot{\xi} \mid \zeta)$ intervienen como notificantes de los noemas categoriales, ${ }^{11}$ predicables y también del juicio ( 2007, p. 35 ss.).

El maestro del Liceo explica que, así como cuando en el alma hay una noción sin patentizar de ella verdad o falsedad y otras veces la hay también de modo que necesariamente ha de darse una de las dos cosas, así también ocurre en el sonido articulado (De int. 16a 9-11). De igual manera, los verbos notifican un significado puesto que son nombres que co-significan que algo pertenece a algo actualmente (De int. 16b 6-11). De modo tal que los nombres y verbos se asemejan al noema sin composición ni división, cuando no se añade nada más; puesto

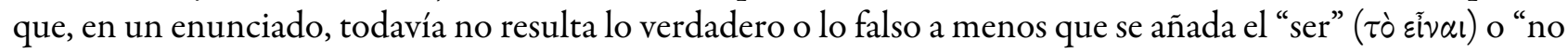

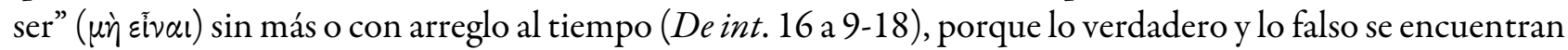

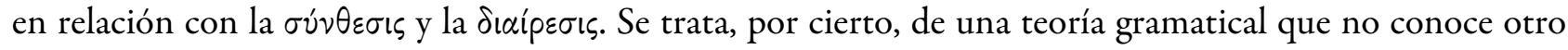
criterio más que el semántico, ${ }^{12}$ hasta el extremo de llegar a considerar los casos o inflexiones del nombre y el verbo no como meras variantes morfosintácticas, sino como alteraciones del significado del nombre y el verbo por antonomasia que son el nominativo y las formas del indicativo presente, respectivamente (De int. 16a 32,16 b 16-18). ${ }^{13}$

Ross (1957, p. 44 ss) interpreta que el análisis del fenómeno lingüístico, tal como se ofrece en las primeras líneas de De int. (16a 7), parecería obedecer a una concepción representacionista del conocimiento. Aristóteles dice que las afecciones del alma ( $\tau \dot{\alpha} \pi \alpha \theta \dot{\eta} \mu \alpha \tau \alpha \tau \tilde{\eta} s \psi v \chi \tilde{\eta} s)$ son semejanzas o imágenes de los objetos reales $(\tau \grave{\alpha} \pi p \alpha ́ \gamma \mu \alpha \tau \alpha)$. De acuerdo con este modo de ver, el juicio no sería el establecimiento de conexiones existentes en la realidad, sino de conexiones o divisiones - en el caso del juicio negativo- de los contenidos noéticos o conceptos (De int. 16a 9-14). En la medida en que el juicio, afirmativo o negativo, se da acerca de aquellos objetos en los que cabe el error o la verdad, es presentado en De anima (430 a 27) como el acto de reunión de varios conceptos que, compuestos, constituyen entre sí una unidad, como si el juicio consistiera en unir formalmente los conceptos que se encuentran separados en el espíritu. Por tanto, al considerar el juicio como una antítesis o separación de conceptos, la doctrina implícita de la verdad o falsedad apuntaría a mostrar que un juicio es verdadero cuando une entre sí dos conceptos ( $\mathrm{A}^{\prime}$ y $\mathrm{B}^{\prime}$ ) que son, respectivamente, las imágenes de los objetos (A y B) asociados en la realidad, y los separa cuando son imágenes de dos objetos que están disociados en la realidad; o bien que es falso en ambos casos contrarios. Ello no obstante, Ross insiste en el hecho de que tal comprensión de la verdad como correspondencia no representa el mejor pensamiento de Aristóteles sobre esta materia. En otro pasaje, el estagirita asevera sin ambages que el pensamiento se dirige directamente a la realidad y aduce que el juicio es verdadero cuando afirma lo que en la realidad está 
unido entre sí y niega lo que realmente está separado; mientras que yerra cuando el pensamiento está en contradicción con las cosas reales (Met. 1051b 2-6). La concepción de Aristóteles acerca del conocimiento está lejos de presentarse en términos tales como si la estructura del pensamiento copiase la estructura de la realidad.

En el resto de los capítulos, Aristóteles definirá el nombre (cp. 2), el verbo (cp. 3) y el enunciado (cp. 4). De los enunciados, separa para un estudio detenido el enunciado apofántico o asertivo que es, per definitionem, el susceptible de adquirir la condición de verdad o falsedad. Acotado de esta manera el objeto del tratado, el autor se ocupará en la consideración de la diferencia entre las aserciones simples o compuestas (cp. 5), en vista de lo cual el criterio será ontológico-semántico, es decir, se dirigirá al carácter unitario o múltiple de la realidad designada por el enunciado; la diferencia entre afirmación y negación, esto es, la cualidad lógica del enunciado (cp. 6); la cuantificación y oposición de las aserciones (cp. 7 y 8); el problema de la verdad en las aserciones de hechos futuros (cp. 9); las relaciones de consecución entre aserciones afirmativas de predicado negativo y, a la inversa, de aserciones negativas de predicado positivo (cp. 10 y 11); la oposición y consecución entre las aserciones modales (cp. 12 y 13) y, finalmente, un estudio sobre la contrariedad en el que se distingue entre la contrariedad en la aserción y la aserción de contrarios (cp. 14). ${ }^{14}$

\section{El análisis del nombre y del verbo}

En relación con la proposición, Aristóteles toma como punto de partida el análisis platónico del nombre y del verbo (De int. 16a 1, 19b 10; Ross, 1957, p. 46 ss.). En el Sofista (261e 4-262a 7), Platón dice:

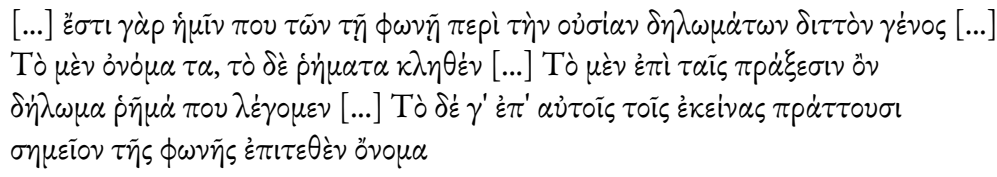

Pues el género que permite exhibir el ser mediante un sonido es doble [...] Uno se llama nombre; el otro, verbo [...] Llamamos verbo al que muestra las acciones [...] Mientras que el nombre es el signo sonoro aplicado a los autores de aquéllas. ${ }^{15}$

En el pasaje citado es expuesto el axioma que preside la concepción platónica del discurso, sea éste de índole verdadera o falsa: sus términos — nombre y verbo- expresan el ser (ov̉ $\sigma i \alpha$ ), de modo tal que toda referencia a objetos inexistentes queda, por sí misma, fuera de tal explicación.

Sobre la base de este esquema conceptual, Aristóteles procede en la exposición de sus propias distinciones. Dice que un nombre es un sonido con significado establecido por convención, sin ninguna referencia al tiempo y cualquiera de cuyas partes no es significativa por separado (De int. 16a $19 \mathrm{ss}$ ). Un verbo, entretanto,

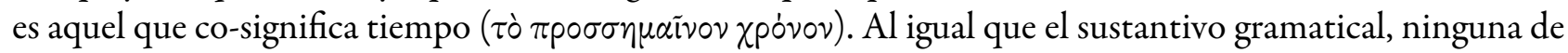
sus partes tiene significado por separado y, además, es signo de lo que se dice acerca de otro, esto es, expresa un significado definido de alguna cosa en relación con otra. Esto quiere decir que el verbo, en sí mismo, no es nada sino que co-significa con arreglo al tiempo una cierta composición que no es posible concebir sin los componentes (De int. $16 \mathrm{~b} 6 \mathrm{ss}$ ).

Bajo la categoría de nombre, en la cual se incluye tanto los nombres propios y comunes como los adjetivos calificativos, se entiende una voz dotada convencionalmente de cierto significado que, a diferencia del verbo, no indica tiempo (De int. 16a 19-21). El verbo, por el contrario, comporta en su significación un aspecto irreductiblemente temporal. Así lo muestra el ejemplo puesto por Aristóteles al señalar la diferencia entre el

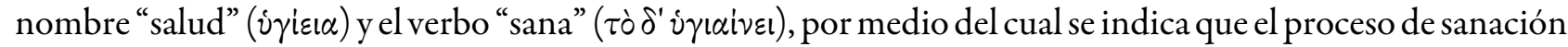
se lleva a cabo en un tiempo presente (De int. $16 \mathrm{~b} 5-9$ ). El verbo es definido por Aristóteles a partir de su función sintáctica habitual, es decir, la función de predicado (De int. 16b 6-7). Desde un aspecto semántico, el verbo es considerado como la palabra que lleva aparejada la referencia paralela al tiempo. Sin embargo, la función predicativa tiene primacía frente a la co-significación de tiempo (Candel Sanmartín, 2007, p. 304, n. 30). 
Vigo recalca el hecho de que esta distinción no es del todo precisa, pues el estagirita piensa en realidad que la gran mayoría de los verbos con los que cuenta el lenguaje poseen una naturaleza mixta, a la vez nominal y verbal, pues al aspecto verbal puro - el cual expresa la unión de sujeto y predicado en la totalidad del enunciado conjuntamente con el tiempo- se añade también un aspecto de significación nominal. En tal sentido, Aristóteles pareciera sugerir que, en el caso de los verbos diferentes de la cópula "es", la significación podría analizarse según el esquema: "es + predicado nominal". Por consiguiente, haciendo caso omiso de otras diferencias concernientes a los tiempos y modos verbales, todo enunciado compuesto a partir de un nombre y un verbo diferente de la cópula "es" podría ser formalizado en los siguientes términos: "sujeto + cópula + predicado nominal". Así, $v$. gr., "X conoce el bien" sería equivalente a "X es conocedor del bien" (Anal. pr. 51b 10-16; Vigo, 2006, p. 30 ss).

El maestro del Liceo también reconoce, junto con el nombre y el verbo, otros elementos que denomina "nombre indefinido" y "verbo indefinido", tales como "no-hombre" o "no está enfermo", y los designa así porque pueden afirmarse de toda especie de cosas, tanto existentes como no existentes (De int. 16a 30-33, b 12-15). A propósito de esto, Ross (1957, p. 46) remarca que: "El De interpretatione, que rastrea con un interés apasionado las variedades lingüísticas posibles de la proposición, se ocupa mucho de estas formas, pero Aristóteles se da cuenta de que en la vida del espíritu la pura negación carece de importancia, e ignora casi completamente estas formas en sus demás obras lógicas”.

\section{La determinación del enunciado}

El cp. IV de De int. (16b 27 ss.) es el pasaje que más interesa con respecto al tema específico del enunciado, dado que allí Aristóteles dilucida qué es el enunciado, sus clases y particularmente la proposición asertiva o

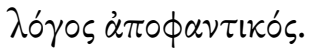

En los Analytica priora (24a 15-17), el estagirita define la proposición como "un enunciado afirmativo o negativo de algo acerca de algo: este enunciado, a su vez, puede ser universal o particular o indefinido". ${ }^{16}$ En De int., manifiesta que un enunciado es un sonido significativo $(\phi \omega \nu \eta \dot{~} \sigma \eta \mu \alpha \nu \tau i k \eta \dot{)}$ cualquiera de cuyas partes es significativa por separado como algo que se dice, pero no como una aseveración de carácter afirmativo o negativo. En este caso, "hombre" significa algo pero no que "es" ( añadiera algo a ese nombre, Aristóteles asevera que tal sería el caso de una afirmación o una negación. Dentro del nombre como unidad semántica simple, una sílaba empero no es significativa por separado, sino tan solo como mero sonido. Aquí, el maestro del Liceo acude a un caso límite para señalar que, aun cuando una sílaba tuviese significado por sí misma en otra cadena morfosintáctica, no lo tendría al formar parte de una palabra, como ocurre con el término griego $\mu \tilde{\varsigma} \varsigma$ que se traduce por "ratón”, cuyo sufijo - v५, con espíritu áspero y en otro contexto, significa "cerdo"( $\tilde{\iota} \varsigma)$.

A partir del nombre y el predicado puede examinarse, por consiguiente, el enunciado como un resultado que surge de tales componentes. Su estructura formal básica es la que se da en la relación general de un sujeto - nombre - con un predicado - verbo o construcción verbal de tipo "verbo + nombre"- (De int. $16 \mathrm{~b}$ 24-32). En este ámbito de la relación S-P queda abierta la posibilidad para hablar de verdad o falsedad en la proposición, toda vez que los términos simples no son, en sí mismos, ni verdaderos ni falsos. Del nombre tomado por separado - v. gr. "hombre" - solo puede preguntarse si significa algo, pero no si es verdadero o falso. A fin de plantearse tales interrogantes, es menester tomar los términos en conexión con un correspondiente verbo y considerarlos dentro de la estructura del enunciado (De int. 16a 9-18). En su sentido más habitual, los términos verdad y falsedad se aplican solo en el caso de los enunciados y, por extensión, de los razonamientos, en la medida en que evidencien adecuadamente los objetos o estados de cosas a los que se refieren en cada caso. 
En otros contextos, Aristóteles tematiza las nociones de verdad o falsedad en relación con los entes no compuestos (Met. 1051b 17-33) y es muy probable que apunte por medio de ello a la función designativa e identificadora de las expresiones nominales, empleadas para nombrar y clasificar objetos. Este punto se formula diciendo que un enunciado de la forma S-P será verdadero si presenta unido lo que está efectivamente unido (afirmación), o bien si presenta como dividido lo que ciertamente está dividido (negación). La composición y la división se refieren, de esta manera, a la relación mantenida entre los términos $\mathrm{S}$ y $\mathrm{P}$ a través de la cópula "es" y de su negación "no es". Por el contrario, si el enunciado patentiza como compuesto lo que está dividido y como dividido lo que está compuesto, entonces, es falso (Met. 1027b 20-23). En palabras de Aristóteles: "es verdadera la proposición que afirma que lo-que-es es y lo-que-no-es no es; mientras que será falsa la que afirme que lo-que-es no es o bien que lo-que-no-es es" (Met. 1011b 25-27).

El estagirita sostiene que todo enunciado es significativo pero no como un instrumento natural (öp $\gamma \alpha \nu \circ v)$, sino por convención ( $\kappa \alpha \tau \dot{\alpha} \sigma \nu \nu \theta \dot{\eta} \kappa \eta \nu)$; lo que quiere decir que la relación entre un enunciado y la realidad no es la misma que se da entre la realidad misma y un instrumento, cuya naturaleza o finalidad implicaría una determinada actividad para operar sobre ella. A continuación, asevera que no todo enunciado es asertivo sino solo aquel en el que se da el decir verdad o falsedad. Y arguye que no en todos los enunciados se da, pues en el caso de la plegaria ( $\dot{\eta} \varepsilon \dot{x} \chi \grave{\eta})$, que es por cierto un enunciado, no hay verdad o falsedad. Lo verdadero y lo falso, por su parte, giran en torno a la composición y la división (De int. 16 a 13). A fin de cuentas, Aristóteles puntualiza que el examen del tratado en cuestión tiene por objeto el enunciado asertivo, mientras que reserva el análisis de los otros tipos de enunciados para la Retórica o la Poética. De esta manera se infiere que, dentro de los enunciados susceptibles de ser proferidos, una clase responde al carácter de enunciado asertivo: aquel en el que se da verdad o falsedad ( $\tau \grave{\partial} \grave{\lambda} \lambda \eta \theta \varepsilon \dot{\varepsilon \varepsilon \iota \nu} \ddot{\eta} \psi \varepsilon \dot{\delta} \delta \varepsilon \sigma \theta \alpha \iota)$, motivo por el cual ese único tipo de enunciado será objeto de la teoría en curso, mientras que los demás deberán estudiarse en otras disciplinas y a partir de otros métodos.

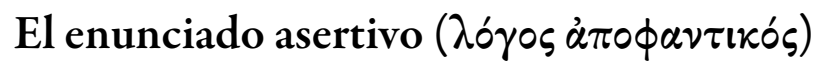

De acuerdo con lo expuesto anteriormente, se ha reparado en la peculiaridad de que si bien la verdad y falsedad se dan únicamente en el ámbito de la relación S-P, constitutiva de todo enunciado, no todo enunciado de la forma S-P reúne las condiciones que le permiten ser una declaración asertiva. En orden a la condición apofántica, Aristóteles discrimina solo los enunciados que poseen el verbo en modo indicativo y cumplen una función esencialmente declarativa. Por otra parte, aquellos enunciados que notifiquen efectivamente un determinado estado cosas pero por medio de otros modos verbales - como ocurre en el caso del discurso parenético, desiderativo o bien exclamativo- no caerán en el ámbito de la diferenciación verificativa, puesto que no son verdaderos o falsos, es decir, no constatan la existencia o no-existencia de sus referentes en el plano de la significación (De int. 16b 33-17a 7).

El modo verbal indicativo posee el tipo de fuerza asertiva que es condición sine qua non se dé la verdad o falsedad de algo. Cuando la conexión S-P posee esta fuerza asertiva, el enunciado correspondiente es designado por Aristóteles enunciado declarativo o apofántico (De int. 17a 7), el único tipo de proposición al

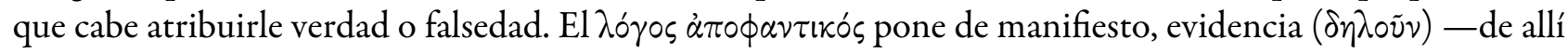

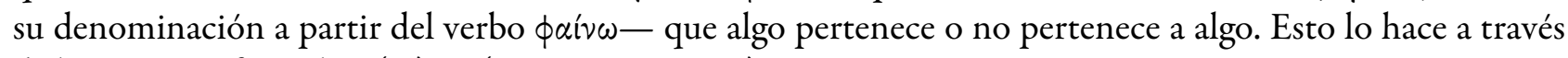
de la conexión formal "S (es) P" (De int. 17a 15-22).

A propósito del carácter peculiar de la aserción como enunciado que comporta verdad o falsedad, debe decirse que Aristóteles cifra esa peculiar característica de la ả $\pi$ ó $\phi \alpha \nu \sigma \iota \varsigma$ o del $\lambda o ́ \gamma \sigma \varsigma \dot{\alpha} \pi \circ \phi \alpha \nu \tau \iota \kappa o ́ \varsigma$ en la posición de existencia del ente, como se advierte en De int. 16 a 12-18 y 16b 19-25, donde distingue la diferencia entre "significar algo" y "significar la existencia de algo". Todos los nombres — sujetos y verbos- significan algo, es decir, se corresponden con un contenido mental ( $\nu o ́ n \mu \alpha)$; aunque, por sí mismos, no dicen si ese significado está actualmente representado en un objeto real $(\pi p \tilde{\alpha} \gamma \mu \alpha)$ o no. Tal posición de existencia solo se da con la 


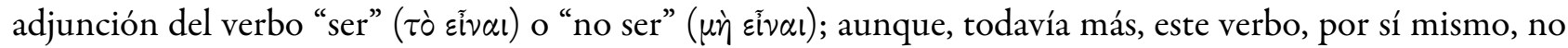
establece o excluye la existencia de la cosa real: "ni siquiera ser o no ser es signo de la cosa real" dice Aristóteles (De int. 16b 21), sino que solamente "co-significa” la existencia en la realidad de lo significado por la síntesis noética, cuyos términos expresan por medio de su unión la estructura más englobante del enunciado.

El हैं $\tau$ l, en efecto, no es un género, de esta manera no puede ser predicado. Por consiguiente, la composición o la división fundamental a la que se refiere la exigencia aristotélica como conditio de verdad o falsedad no alude necesariamente a la composición o división predicativa, puesto que, de lo contrario, una proposición del tipo "Sócrates es" no podría ser suficiente para reclamar su valor de verdad. En relación con esto, Anton Mlinar (2012, pp. 121-129) asevera que la condición de verdad o falsedad expresada en el $\lambda o ́$ jos

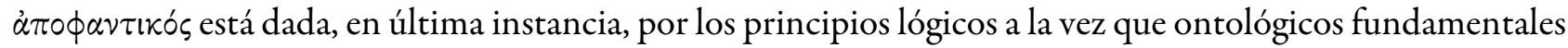
de la metafísica y ciencia aristotélicas: la estructura categorial inherente a todo ente que posibilita, por lo demás, toda conceptualización. Una definición será verdadera no porque incluya en ella la existencia de algo en sí misma, sino por su posible - y, en consecuencia, demostrable - comprensión noemática del orden categorial. Solo en virtud de este orden categorial informante de los entes - que hace posible su aprehensión correspondiente- la significación, la composición y la división son susceptibles de verdad o falsedad.

Esta concepción de lo verdadero o falso de los enunciados asertivos, en cuanto posición -afirmación - o exclusión - negación - de existencia, co-significada a su vez por el verbo ser, hace que Aristóteles privilegie la forma atributiva de los enunciados por encima de la mera forma predicativa. Por medio del carácter copulativo puede apreciarse mejor la diferencia entre el contenido noético — significativo- de un enunciado (expresado por los términos $\mathrm{S}$ y $\mathrm{P}$ ) y su forma apofántica (co-significativa de verdad - existencia - o falsedad -inexistencia). Tal forma está expresada por el verbo eĩval y Aristóteles lo coloca siempre en primera posición para señalar su función modal respecto del contenido. El hecho de que el estagirita coloque el verbo ser en primera posición dentro de la estructura del enunciado obedece, precisamente, a su intención por aislar al máximo y poner de relieve el elemento funcional, específicamente asertivo, que caracteriza al enunciado apofántico, diferenciándolo asimismo de otros tipos de enunciado (Candel Sanmartín, 2007, p. 311, n. 58).

En última instancia, Aristóteles remite su concepto de "ser" al análisis gramatical, en el que, a diferencia de la confusión platónica del ser como un predicado generalísimo, se revela la naturaleza funcional de ese término clave. Según la interpretación de Candel Sanmartín al respecto (2007, p. 305, n. 35; pp. 316-317, n. 78), Aristóteles pretende aislar el elemento puramente asertivo de los elementos designativos del enunciado. Entiende el verbo "ser", por una parte, como el verbo por excelencia, el que más claramente se diferencia del nombre, puesto que es el menos provisto de contenido noético, permitiendo así detener el pensamiento sobre un significado determinado. Lo esencial de un verbo, empero, es la co-significación de tiempo aplicada a algo, que es tanto como decir, la afirmación o negación de la existencia de algo — por sí mismos, los verbos no indican si existe algo o no. Por otra parte, ni siquiera el verbo ser puede tomarse en sí mismo sin la composición con algo como significante de existencia en general, ya que el ser no mienta género alguno ni entidad de nada (Met. 998b 22 ss., 1001a 5-6, 10410b 18, 1045b 3-7, 1052b 23, 1059b 27-33). Cabe agregar que al verbo ser no se lo puede llamar con propiedad ni nombre ni verbo, toda vez que se lo puede llamar indistintamente de una manera o de otra. Lo propio de ese verbo es otorgar al enunciado su carácter asertivo o declarativo, es decir, de referencia actualizada a la realidad, por más que se identifique con la categoría de los verbos y que cumpla con una función más propiamente verbal o predicativa cuando actúa como segundo elemento de la aserción (De int. 19b 15-22).

\section{La cualidad lógica de las aserciones}

En atención a la cualidad lógica de las proposiciones y desde el punto de vista del tipo de conexión que se establece entre el término $S$ y el término $P$, hay para el estagirita dos especies fundamentales de enunciados 
declarativos, a saber, los afirmativos y los negativos. El primer enunciado asertivo singular (zí $)$ es la afirmación

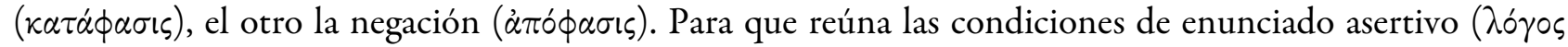
$\dot{\alpha} \pi \circ \phi \alpha \nu \tau i k o ́ s)$ toda proposición debe constar de un verbo o una inflexión de un verbo. Si al concepto de "hombre" no se le añade el "es" o el "será" o el "era", no se obtiene en modo alguno un enunciado asertivo. El verbo y el nombre por separado son solo enunciaciones pero no aserciones. El enunciado asertivo singular se refiere al que indica una sola cosa o al que tiene unidad gracias a una conjunción; son múltiples, en cambio, los que ni indican una sola cosa ni están unidos por una conjunción. De esta manera, solo hay dos tipos de proposiciones asertivas: las afirmaciones y las negaciones. Cualquier otro tipo de enunciado asertivo complejo se reducirá a una suerte de combinación entre afirmaciones y negaciones, unidas por una conjunción. De la presente taxonomía se desprende el hecho de que la proposición asertiva simple será aquella que afirme (es

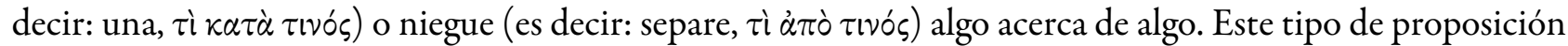
es un sonido significativo acerca de si algo se da o no se da, con arreglo a la división de los tiempos; la otra, en cambio, será un discurso ya compuesto.

En su mayor parte, tanto la afirmación cuanto la negación son tratadas de manera coordinada, salvo en algunas ocasiones donde el estagirita considera la afirmación con anterioridad a la negación (De int. 17a 8 ss., Anal. post. 86b 33-36). Así como toda afirmación es la aceptación de una conexión sugerida, la negación será el rechazo de aquella conexión (Met. 1017a 31-35). Incorporando una terminología que llegará a ser canónica en el derrotero de la historia de la lógica, el maestro del Liceo califica la afirmación como una operación de

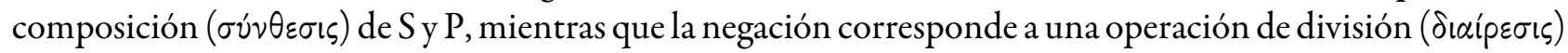
o separación de esos términos (De int. 16a 9-13; Met. 1027b 20-23, 1051b 2-5). En algunos casos, es posible advertir el hecho peculiar de que la estructura del enunciado implica tanto el momento de la diferenciación funcional de $S$ y $\mathrm{P}$, como el momento de su vinculación sintética en una unidad significativa mayor ( $D e$ anima 430b 1-4). Esto implica la idea de que todo enunciado, con independencia de su cualidad lógica, puede ser descripto al mismo tiempo en términos de división y de composición. En relación con esto último cabe remarcar, entonces, que tanto el enunciado afirmativo cuanto el negativo comportan ambos una estructura esencialmente analítica y sintética a la vez, en la medida en que distinguen funcionalmente y conectan los términos elementales (S-P) de la proposición (Vigo, 2006, p. 32 ss.).

Con todo, Ross (1957, pp. 48-49) considera que en Aristóteles se aprecian tres razones plausibles para admitir la afirmación como anterior a la negación: (1) porque se expresa en una forma lingüística más sencilla; (2) porque, además, una conclusión negativa requiere una premisa afirmativa, mientras que una conclusión afirmativa no puede ni debe tener una premisa negativa (Anal. post. 86b 34-39); ${ }^{17}$ (3) porque la afirmación, a diferencia de la negación, confiere una información más precisa acerca del sujeto (Met.996b 14-16).

De todas maneras y más allá de las nociones vinculadas con el empleo de la composición y la división, lo fundamental es que, en cuanto constituyen las dos posibles formas de enunciado desde el punto de vista de la cualidad lógica, afirmación y negación son siempre opuestas entre sí. De modo que si se toma un enunciado afirmativo junto con su correspondiente negativo, se llegará a la conclusión de que, en rigor, no pueden ser ambos verdaderos, al mismo tiempo y respecto de lo mimo, puesto que, de serlo, atentarían contra el principio más firme de todos (De int. 17a 26-37, Met. 1005b 19-22). ${ }^{18}$

\section{A MODO DE CONCLUSIóN}

(1) Sobre la base de los desarrollos realizados, cabe señalar en primer lugar que el estagirita distingue concretamente el enunciado asertivo de otros tipos de enunciado cuya función no es stricto sensu de naturaleza

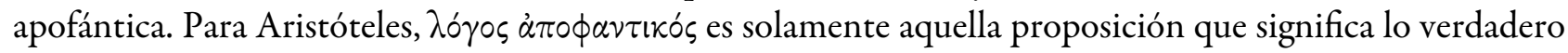
o lo falso.

(2) Heidegger, por su parte, generaliza para todo tipo de discurso su carácter apofántico. Para Heidegger, en todo acto de habla se tiene un 'sobre qué' que es propio de lo dicho en cuanto tal -i. e. aquello de lo cual 
se habla- - y hay también, junto con ello, una comunicación lingüística en los términos de una participación entre hablantes. De acuerdo con su comprensión del sentido de $\alpha \pi \circ \phi \alpha i v \varepsilon \sigma \theta \alpha$, en el $₫ 7$ B de $S u Z$ se refiere a la estructura existencial del habla examinada más adelante en el $\$ 34$.

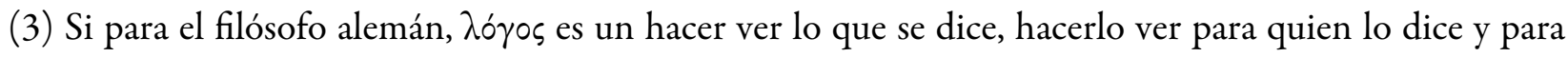
quienes interactúan, el decir existencial puede ser remitido, por lo tanto, a todo modo de decir, todo tipo de frase, puesto que cada $\lambda o ́$ yos comprende un tema a partir del cual se dice lo que se dice. Para Aristóteles, por el

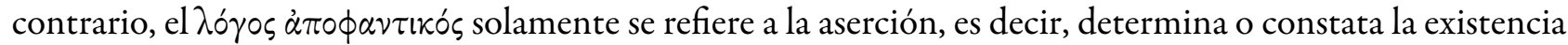

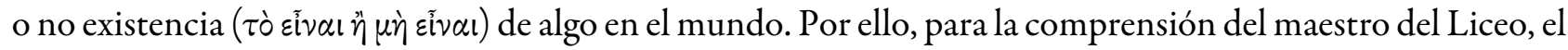
acto de habla supone un estado de cosas en orden al cual el lenguaje se refiera en su carácter a la vez notificador y simbólico.

\section{REFERENCIAS}

Allen, T. W. (Ed.). (1931). Homeri Ilias. Oxford: Clarendon Press.

Anton Mlinar, I. (2012). El ésti del lógos apophantikós y la verdad de los entes no compuestos en Aristóteles. En M. Rodríguez de Grzona (Ed.), Estudios sobre Aristóteles (pp. 121-129). Mendoza: SSyCC.

Aristóteles (1982, reimpr. 2007). Ética Nicomáquea, Ética Eudemia y Acerca del Alma. Intr. de T. Martínez Manzano y T. Calvo Martínez, trad. y notas de J. Pallí Bonet y T. Calvo Martínez. Madrid: Gredos.

Aristóteles (1982, reimpr. 2007). Física. Intr., trad. y notas de G. Rodríguez de Echandía. Madrid: Gredos.

Aristóteles (1982, reimpr. 2007). Metafísica. Intr., trad. y notas de T. Calvo Martínez. Madrid: Gredos.

Aristóteles (1982, reimpr. 2007). Retórica. Intr., trad. y notas de Q. Racionero. Madrid: Gredos.

Aristóteles (1982, reimpr. 2007). Tratados de lógica. Introd., trad. y notas de M. Candel Sanmartín. Madrid: Gredos. Aristóteles. (2000). Política. Trad. y notas de M. G. Valdés. Madrid: Gredos.

Ast, F. (1956). Lexicon Platonicum sive Vocum Platonicarum Index. Vol. II. Bonn: Rudolf Abelt Verlag.

Astrada, C. (1952). La revolución existencialista. Hacia un humanismo de la libertad. La Plata: Ediciones nuevo Destino. Aubenque, P. (1987). El problema del ser en Aristóteles. Trad. de Vidal Peña. Madrid: Taurus.

Bailly, A. (195016). Dictionnaire Grec-Français. Paris: Librairie Hachette.

Bertorello, A. (2008). El límite del lenguaje. La filosofia de Heidegger como teoría de la enunciación. Buenos Aires: Biblos. Boeder, H. (2003). Das Wahrheits-Thema in der Ersten Epoche der Philosophie. Sapientia, 58, 5-22.

Boeder, H. (2003). Il tema della verità nella prima epoca della filosofia. Il Pensiero rivista di filosofia, 44, 21-33.

Bonitz, H. (1955). Index Aristotelicus. Graz: Akademische Druck-U. Verlagsanstalt.

Bonitz, H. (1960). Aristotelis Metaphysica Commentarius. Hildesheim: Georg Olms Verlagsbuchhandlung.

Bywater, I. (Ed.). (1894). Aristotelis ethica Nicomachea. Oxford: Clarendon Press.

Burnet, J. (Ed.). (1900). Sophista. En Platonis opera (vol. 1). Oxford: Clarendon Press.

Chantraine, P. (1974). Dictionnaire étymologique de la langue grecque. Histoire des mots. t. III. Paris: Éditions Klincksieck.

Chichi, G. M. (1997). El concepto aristotélico de éndoxon según la técnica de discusión de Los Tópicos. En H.J. Padrón (Ed.), Aristóteles (pp. 180-187). Mendoza: Editorial de la Facultad de Filosofía y Letras.

Coseriu, E. (1977). L’arbitraire du signe. Sobre la historia tardía de un concepto aristotélico. En Tradición y novedad en la ciencia de lenguaje. Estudios de historia de la lingüistica (pp. 13-61). Madrid: Gredos.

Escobar, S. (2004). Lógos apofántico y apertura al mundo. El carácter derivado de la verdad proposicional en Logik. Die Frage Nach Der Wabrheit. Anuario Filosófico, XXXVII (2), 361-390.

Evans Civit, J. (2007). La esencia en su acaecerse ontológico. Mendoza: Editorial de la Facultad de Filosofía y Letras. Evans Civit, J. (Ed.). (2010). Antologia del Index Aristotelicus de H. Bonitz. Buenos Aires: Santiago Arcos editor. 
Fernández, C. J. (2011). La controversia medieval sobre el triángulo semántico de Aristóteles. En S. Filippi (Ed.), Controversias filosóficas, cientificas y teológicas en el pensamiento tardo-antiguo y medieval (pp. 359-372). Rosario: Paideia Publicaciones.

García Yebra, V. (Ed.). (19982). Metafísica de Aristóteles. Ed. Trilingüe. Madrid: Gredos.

Glare, P. G. W. (1968). Oxford Latin Dictionary. London: Oxford University Press.

Heidegger, M. (1994). Logos. En Conferencias y artículos (pp. 179-199). Trad. de E. Barjau. Barcelona: Serbal.

Heidegger, M. (1994). Poéticamente habita el hombre. En Conferencias y artículos (pp. 163-178). Trad. de E. Barjau. Barcelona: Serbal.

Heidegger, M. (2001). Sein und Zeit. Tübingen: Max Niemeyer Verlag.

Heidegger, M. (2003). Sery tiempo. Trad., pról. y notas de J. E. Rivera C. Madrid: Editorial Trotta (Versión electrónica: http://www.philosophia.cl/ Escuela de Filosofía Universidad ARCIS).

Heidegger, M. (2006). Carta sobre el Humanismo. Trad. de H. Cortés y A. Leyte. Madrid: Alianza Ed.

Homero (1982). Odisea. Intr. de M. Fernández Galiano, trad. de J. M. Pabón. Madrid: Gredos.

Homero (1991). Ilíada. Trad., pról y notas de E. Crespo Güemes. Madrid: Gredos.

Kant, I. (1956). Kritik der reinen Vernunft. Hamburg: Meiner.

Kant, I. (20092). Crítica de la razón pura. Intr., trad. y notas de M. Caimi. Buenos Aires: Colihue.

Liddell, H. G. \& Scott, R. (Eds.). (19669). Greek-English Lexicon. Oxford: University Press.

Minio-Paluello, L. (Ed.). (1949). Aristotelis categoriae et liber de interpretatione. Oxford: Clarendon Press.

Molina, J. (2012). Lógica hermenéutica. Reflexiones acerca de sus antecedentes en Heidegger. http://textos.pucp.edu.pe /pdf/1694.pdf.

Mühll, P. von der (Ed.). (1962). Homeri Odyssea. Basel: Helbing \& Lichtenhahn.

Muñoz Pérez, E. V. (2013). Metafísica, lógica y mundo. Una mirada antropológica de Los conceptos fundamentales de la Metafisica: mundo, finitud, soledad, 1929/30, de Martin Heidegger. Revista de Filosofía, 69, 215-225.

Platón (1982, reimpr. 2007). Diálogos V. Intr., trad. y notas de Ma I. Santa Cruz, Á. Vallejo Campos y N. L. Cordero. Madrid: Gredos.

Ross, W. D. (Ed.). (1950). Aristotelis physica. Oxford: Clarendon Press.

Ross, W. D. (1957). Aristóteles. Trad. de D. F. Pró. Buenos Aires: Editorial Sudamericana.

Ross, W. D. (Ed.). (1957). Aristotelis politica. Oxford: Clarendon Press.

Ross, W. D. (Ed.). (1958). Aristotle's metaphysics. 2 vols. Oxford: Clarendon Press.

Ross, W. D. (Ed.). (1958). Aristotelis topica et sophistici elenchi. Oxford: Clarendon Press.

Ross, W. D. (Ed.). (1959). Aristotelis ars rhetorica. Oxford: Clarendon Press.

Ross, W. D. (Ed.). (1961). Aristotle. De anima. Oxford: Clarendon Press.

Ross, W. D. (Ed.). (1964). Aristotelis Analytica priora et posteriora. Oxford: Clarendon Press.

Vigo, A. (2006). Aristóteles. Una introducción. Santiago de Chile: Instituto de Estudios Sociales.

Yarza, I. (1997). Universalidad de la dialéctica aristotélica. En H. J. Padrón (Ed.), Aristóteles (pp. 133-140). Mendoza: Editorial de la Facultad de Filosofía y Letras.

\section{Notas}

1 Para las referencias, junto con el $\S$, se consigna también la p. según la versión de J. E. Rivera (Heidegger, 2003).

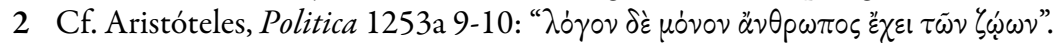

3 Es el problema con que se enfrenta Kant (KrV A 154, B 193). Una vez dilucidado el esquematismo de los conceptos puros del entendimiento, se debe dejar sentado el sistema de todos los principios del entendimiento puro.

4 Sobre la verdad de los entes no-compuestos, cf. Aristóteles, Met. 1051b 17-1052a 4.

5 En relación con esta presentación cf. Ross (1957, pp. 37 ss.); Vigo (2006, pp. 21 ss.).

6 Se sigue la versión de García Yebra (1998). 
7 Cf. Bonitz (1960, p. 470): "Et hodierni quidem philosophi [...] quoniam in notionibus cognoscendis omnem operam ponunt [...] notionibus universalibus tribuendam putant substantiae dignitatem; veteres autem philosophi non universalem corporis notionem [...] sed singula corpora et ea quidem simplicissima substantias esse censuerunt".

8 Cf. Bonitz (1960, p. 187): "Et hoc quidem loco logikai dyschéreiai eae erunt adversariorum argumentationes, quae non ex ipsa rei refutandae natura, sed unice ek tôn lógon petitae sunt, i. e. inde, quod in formula principii identitas et rei et temporis et reliquorum, quae possunt in censum venire, non satis accuratis notionum finibus circumscripta est [...] Aristoteles enim de rebus agit, logica formalis de notionibus (notio A est A, neque est eadem ac notio non -A). Neque hoc aliud est discrimen, quam quo omnino logica Aristotelica a logica vere formali siungitur [...] in quo discrimine utrum virtus cernatur philosophiae Aristotelicae [...] an vitium [...] non est huius loci quaerere".

9 Para una síntesis de lo descripto en estos apartados cf. Vigo (2006, p. 30 ss.).

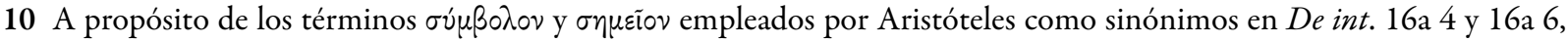
respectivamente, téngase en cuenta la crítica que sobre estas notificaciones realiza Aubenque y que, asimismo, es tomada por Evans Civit (2007, pp. 32-33). Entiende Aubenque (1974, p. 107) que Aristóteles no usa con propiedad el término

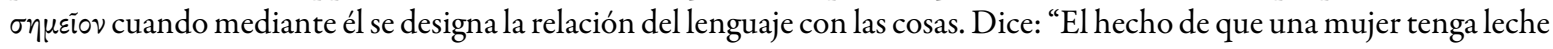
es signo de que ha dado a luz y, en términos generales, el efecto es signo de la causa. Así pues, el signo designa una conexión entre las cosas, y, más aún, fundada en una relación natural (como la de causa a efecto). Desde este doble punto de vista, el $\sigma u ́ \mu \beta 0 \lambda$ ov se opone sin duda al $\sigma \eta \mu \varepsilon \tilde{\imath}$ v, y entonces Aristóteles no usa con propiedad este último término cuando designa con él la relación del lenguaje a las cosas".

11 Evans Civit (2007, p. 46) sugiere reemplazar la voz "noción" por "noema”. El "noema", en cuanto contenido de la actividad noética, es lo que se opone al pensamiento discursivo racional ( $\delta$ íd voı $\alpha$ ). Las voces noema y noesis han sido incorporadas al Diccionario de la lengua española de la Real Academia Española (http://lema.rae.es/drae/?val=noema y http://lema.rae.es/drae/?val=noesis).

12 Para una valoración de la recepción occidental de esta comprensión del lenguaje según Aristóteles cf. Fernández (2011, pp. 359-372).

13 Dice Candel Sanmartín (2007, p. 303, n. 27) que Aristóteles es el primer autor conocido en usar el término $\pi \tau \tilde{\omega} \sigma \iota \varsigma$ ('caída', de allí 'caso', 'inflexión') para designar por medio de él las variantes paradigmáticas de un mismo lexema. En $D e$ int. 2 y 3 el término en cuestión no solo se aplica a las formas de flexión nominal sino, incluso, verbal.

14 Son aserciones contrarias las del tipo: "es todo hombre justo-no es ningún hombre justo"; mientras que son aserciones de contrarios: "es todo hombre justo-es todo hombre injusto".

15 Sigo aquí la versión de Santa Cruz et al. (2007).

16 Sigo en este pasaje la versión de Candel Sanmartín (2007).

17 La conclusión negativa, por cierto, puede tener una premisa negativa y debe haber tanto negaciones como afirmaciones últimas e indemostrables, a saber, las que expresan la mutua exclusión de las categorías (Anal.post. 79 a 33 ss.).

18 El estagirita no reconoce al juicio indefinido como una forma independiente, paralela a la vez al juicio afirmativo y al negativo: A es no-B es una afirmación que contiene una especie particular de predicado, que será necesariamente verdadero o falso, sin que ello reclame más consideraciones al respecto (De int. 20a 32-41). En relación con el caso de los enunciados referidos a eventos futuros contingentes, como del tipo: "mañana habrá o no habrá una batalla naval", según el juicio de Aristóteles, no pueden ser considerados ni como verdaderos ni como falsos al momento de su empleo (De int.9). 